\title{
Protein-responsive polymers for point-of-care detection of cardiac biomarker
}

\author{
Felismina T.C. Moreira, Sanjiv Sharma, Rosa A.F. Dutra, João P.C. Noronha, \\ Anthony E.G. Cass, M. Goreti F. Sales
}

\begin{abstract}

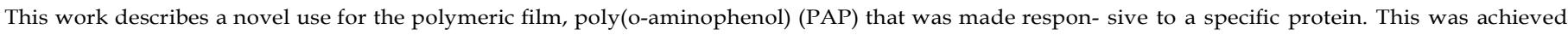

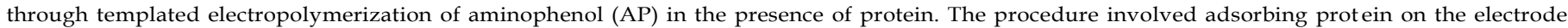

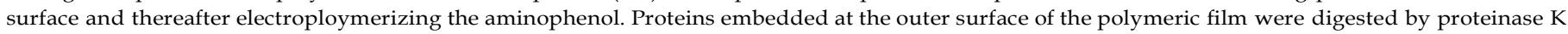

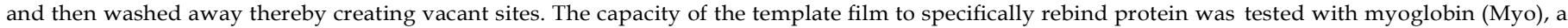

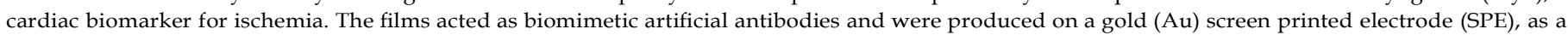
step towards disposable sensors to enable point-of-care applications.

Raman spectroscopy was used to follow the surface modification of the Au-SPE. The ability of the mate- rial to rebind Myo was measured by

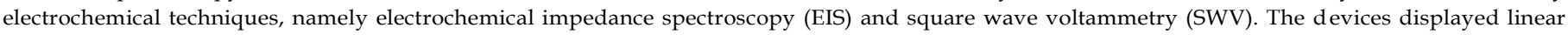
responses to Myo in EIS and SWV assays down to 4.0 and $3.5 \mu \mathrm{g} / \mathrm{mL}$, respectively, with detection limits of 1.5 and

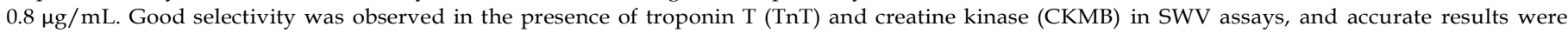

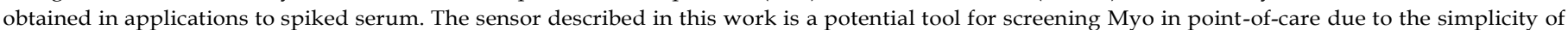
fabrication, disposability, short time response, low cost, good sensitivity and selectivity.
\end{abstract}

Keywords

Biomimetic antibodies, Screen-printed, electrodes, Molecular imprinting, Electropolymerization, Myoglobin, Biosensor

\section{Introduction}

Cardiovascular diseases affect the heart and surrounding blood vessels, and manifest many forms, such as high blood pressure, coronary artery disease, valvular heart disease, stroke, or rheumatic heart disease. These are the largest single cause of death in the EU, accounting $42 \%$ deaths in 2010 [1]. Following cardiovascular biomarkers is a key tool in the fight against cardiovascular diseases, aimed at preserving the patient's life and delivering effective therapies and a successful prognosis for the disease [2-4].

Acute events in cardiovascular diseases are here of special concern, and have been successfully diagnosed by monitoring several well-known biomarkers, such as Creatine kinase isoenzyme (CKMB) $[5,6]$, cardiac troponin I or T (Tn) $[5,7]$, brain natriuretic peptide (BNP) [8] and Myoglobin [3,4]. Timely measurements of these biomarkers demands access to low-cost devices, providing rapid responses and capable of operating in point-of-care.

Current techniques used to determine cardiovascular biomarkers rely on immune/antigen reactions, in a wide range of approaches that include counter-immunoelectrophoresis, latex agglutination quantitative microcomplement fixation assay, and radioimmunoassay $[4,9,10]$. These rely on the great specificity of an antibody towards its antigen, a condition that ensures an easy handling of complex blood samples. However, most of these are not portable and require procedures that can only be made in a clinical laboratory, which is clearly inappropriate for point-of-care applications. The overall procedure may also take much longer than desired in acute events, reaching $2 \mathrm{~h}$. Alternative methods to immunoassays use highly sophisticated chromatographic or electrophoretic procedures [11-13], which are expensive and again unsuitable to carry out analysis in point-of care.

It is therefore important to look for other ways of monitoring biomarkers in cardiovascular diseases, bringing significant long-term economic, health and social benefits to our society. 
(Bio)Sensors could be an alternative, because they allow rapid diagnosis in point-of-care, providing reduced response times and leading to better outcomes of the disease, most especially in acute events $[2,14]$. The receptor element is at the core of the device selectivity, an essential condition for detecting proteins that circulate in the blood at quite low concentrations.

Natural receptors namely antibodies, nucleic acids, and enzymes, have been widely used in biosensors for targeting cardiac biomarkers, leading to electrochemical, optical, mass or magnetic changes [2]. In general, natural receptors offer high selectivity towards a target analyte, but show decreased chemical stability, and are rather expensive. Thus, biomimetic materials have been sought for many years as synthetic receptors.

Molecularly imprinted polymers (MIPs) are among these biomimetic materials and act as plastic antibodies in chemical sensors. In general, MIPs are obtained by 3-D (bulk) or 2-D (surface) imprinting of the complete molecule or parts of it (epitopes) in a rigid polymeric matrix of either organic (vinyl functional derivatives) or inorganic (silica derivatives) materials. The template molecule is subsequently removed and the resulting polymeric network keeps the ability to rebind the template because of the steric and electronic characteristics of the resulting cavities $[15,16]$. Molecular imprinting technology creates materials whose binding specificity is similar to that of antibody-antigen interactions $[17,18]$. These materials offer unique opportunities in terms of reversible inclusion of a bioanalyte [19], mechanical/chemical stability, low price potentially and compatibility with mass manufactures $[18,20-22]$.

While the imprinting of small molecules has been successfully achieved, protein imprinting is still a challenge [23]. The restricted protein mobility within the polymeric network and the weak efficiency/reversibility of binding are major technical hitches. 2-D imprinting seems more reliable in this case, because the binding sites are exposed at the surface allowing easy access/removal of the proteins to/from these. However, in surface imprinting the number of binding sites is rather limited compared to bulk, by the small area available for (re)binding. Thus, a suitable MIP design must be selected.

Few strategies of protein surface imprinting in cardiac biomarker sensing context have been employed so far [23-29], involving surface imprinting procedures on gold [24,28-30], silica $[25,26]$, or carbon [27], while employing different approaches for assembling the polymeric network. Among these, electropolymerization seems to be the simplest approach towards protein imprinting that seems to have been developed first by Panasyuk et al. for a small target analyte [31], and applied later to proteins by Cai et al. [32].

Electropolymerization is typically conducted by leaving the template within the monomer in solution and by applying a suitable potential to enable the formation of a thin film on the electrode surface. Electropolymerization is thus a very simple procedure, enabling the use of different conductive materials of different shape/size, and a close control of the polymer thickness by adjusting the electrochemical conditions under which the polymer is formed [33,34]. However, many of the protein structures, are typically $\mathrm{nm}$ in size, are thus irreversibly entrapped inside the polymeric network and only few are at the outer surface of the newly formed film. The only specific work in this context is that of Karimian et al. most recently published [30]. The authors report a successful electropolymerized imprinted film for troponin, by mixing the cardiac biomarker in the solution with $o$-phenylenediamine, acting as the monomeric unit of the film.

An alternative approach to this procedure, never tested before, as far as we know, would be first adsorbing the proteins to the electrode surface (possibly as multilayers) and to control the thickness of the polymer film, to ensure that most of these proteins are not irreversibly covered and so can be removed. A high density of imprinted cavities is thus expected. Thus, this new concept of electropolymerization for imprinting a protein cardiac biomarker is here described, using Myo as target protein. Myo is a heme protein responsible for the transport of oxygen within cardiac and skeletal muscle cells $[35,36]$ that is released early in the blood in the course of cardiac muscle damage. The measurement of Myo levels within the first few hours after symptom onset in acute events is crucial to diagnosis of cardiac injury. Typical concentrations range from 95 to $472 \mu \mathrm{g} / \mathrm{L}$ [35,37-39].

Overall, Myo imprinted films (MI) were prepared by electropolymerizing $o$-aminophenol around a protein layer previously absorbed to gold. The protein structures located at the outer surface of the film were removed by protease action. A non-imprinted (NI) film was also synthesized in the absence of template to act as control. The resulting biosensor was evaluated by several electrochemical techniques such as CV, EIS and SWV techniques and further applied to the analysis of biological sample.

\section{Experimental}

\subsection{Apparatus}

The electrochemical measurements were conducted with a potentiostat/galvanostat from Metrohm Autolab and a PGSTAT302N, equipped with a FRA module and controlled by Nova software. The Au-SPEs were purchased to DropSens, and have working and counter electrodes made of gold with a reference electrode and electrical contacts made of silver. The diameter of the working electrode was $4 \mathrm{~mm}$. The SPEs were connected to a switch box, also from DropSens (DRP-DSC), allowing their interface with the potentiostat/galvanostat.

Fourier transform infrared spectroscopy (FTIR) measurements were performed using a Thermo Scientific Smart iTR Nicolet iS10, coupled to a SAGA smart accessory, also from Thermo Scientific. Raman measurements were performed using a ThermoScientific DXR Raman microscope system with a $100 \mathrm{~mW} 532 \mathrm{~nm}$ excitation laser, and spectra were made for $5 \mathrm{~mW}$ power and $50 \mu \mathrm{m}$ pinhole aperture.

\subsection{Reagents}

All chemicals were of analytical gradeand water was de-ionized or ultrapure Milli-Qlaboratory grade. Potassium hexacyanoferrate III $\left(\mathrm{K}_{3}\left[\mathrm{Fe}(\mathrm{CN})_{6}\right]\right)$ and potassium hexacyanoferrate II $\left(\mathrm{K}_{4}\left[\mathrm{Fe}(\mathrm{CN})_{6}\right]\right)$ trihydrate, and sodium acetate anhydrous, were obtained from Riedel-deHaen; bovine serumalbumin(BSA), urea, Myo, Troponin $\mathrm{T}(\mathrm{TnT})$, creatine kinase (CKMB), proteinase $\mathrm{K}$ and sodium chloride from Fluka; AP 99\%, 2-(N-Morpholino)ethanesulphonic acid monohydrate $98 \%$ (MES) from Alfa Aesar; and potassium chloride $(\mathrm{KCl})$ from Merck.

\subsection{Solutions}

Stock solutions for calibration curve of $5.0 \times 10^{-6} \mathrm{~mol} / \mathrm{L}$ Myo were prepared in MES buffer $\left(1.0 \not 10^{-2} \mathrm{~mol} / \mathrm{L}, \mathrm{pH} 5.0\right)$. Less concentrated standards were obtained by accurate dilution of the previous solution, in the same buffer. Electrochemical assays were performed with $5.010^{-3} \mathrm{~mol} / \mathrm{L} \mathrm{K}_{3}\left[\mathrm{Fe}(\mathrm{CN})_{6}\right]$ and $5.0 \times 10^{-3} \mathrm{~mol} / \mathrm{L} \mathrm{K}_{4}\left[\mathrm{Fe}(\mathrm{CN})_{6}\right]$, prepared in MES $1.0 \times 10^{-3} \mathrm{~mol} / \mathrm{L}$, $\mathrm{pH}$ 5.0. The selectivity study used $4.0 \mu \mathrm{g} / \mathrm{mL}$ Myo solutions prepared in buffer and solutions of possible interfering species, 
TnT $(0.22 \mu \mathrm{g} / \mathrm{mL})$, and CKMB $(0.5 \mu \mathrm{g} / \mathrm{mL})$, prepared in the same buffer.

\subsection{Electrosynthesis of molecular imprinted and/non-molecular imprinted film}

Prior to electropolymerization, the Au-SPE electrodes were cleaned with ethanol followed by electrochemical cleaning with $0.5 \mathrm{M} \mathrm{H}_{2} \mathrm{SO}_{4}$ by cycling at potential from -0.2 and $1.2 \mathrm{~V}$, for 15 cycles, at a scan-rate of $50 \mathrm{mV} / \mathrm{s}$.

The MI films were produced by covering the working area of the Au-SPE with Myo solution, $5.0 \times 10^{-5} \mathrm{~mol} / \mathrm{L}$, prepared in acetate buffer $\mathrm{pH}$, and let it stand there for $15 \mathrm{~min}$ on. This solution was then replaced by a drop of $1.0 ¥ 0^{-2} \mathrm{~mol} / \mathrm{L} \mathrm{AP}$, in acetate buffer $\mathrm{pH}$ 5 , covering the three-electrodes on the SPE. Polymerization was performed by cyclic voltammetry $(\mathrm{CV})$ between -0.2 and $0.8 \mathrm{~V}$, at a scan rate of $50 \mathrm{mV} / \mathrm{s}$ for 15 cycles. The resulting film was thoroughly washed with deionized water and incubated overnight in Proteinase K (500 $\mu \mathrm{g} / \mathrm{mL}$, prepared in PBS buffer, $\mathrm{pH} 7.4)$, in the dark. The film was finally washed for several times in PBS buffer to remove protein fragments and proteinase $K$, and then rinsed with DI water [40].

NI materials were produced in parallel in the same way, but without the protein incubation step.

\subsection{Qualitative characterization of the films}

All qualitative analysis was conducted directly on the SPE without any prior treatment. MI film with Myo present, MI film after proteinase $\mathrm{K}$ treatment, and NI were analysed by FTIR. A SAGA (Sspecular Apertured Gratzing Angle) accessory was employed in order to ensure that only tangential infrared beams would be collected, thus allowing surface analysis. The number of scans was set to 256, the resolution to 8, apodization of Happ-Genzel, Mertz Phase correction, and a background gain of 8 , from 400 to $4000 \mathrm{~cm}^{-1}$ wavenumber.

Raman microscopy was carried out using a Thermo Scientific DXRRamanmicroscope, equipped witha532nmlaser. Theaverage signal-to-noise ratio (peak height/RMS noise) was measured using standard polystyrene, full-range grating, $15 \mathrm{~s}$ measurement time, $5 \mathrm{~mW}$ laser power at sample, and $25 \mu \mathrm{m}$ slit aperture.

\subsection{Binding Isotherm studies}

The adsorptions dynamics of MI films before and after electrochemical cleaning with PBS buffer and of NI films was measured by SWV assays. This measurement was conducted by adding Myo standards ranging from 0.053 to $53.33 \mu \mathrm{g} / \mathrm{mL}$, prepared in buffer, to the electrodes. A $5 \mathrm{~min}$ period of incubation was allowed before adding the redox probe for subsequent SWV measurements.

A Langmuir isotherm model (equation 1) was applied to the experimental data, where $I_{\mathrm{S}}$ was the normalized current-density (in $\mathrm{mA} \mathrm{cm}^{-2}$ ), $S$ the concentration of Myo (in $\mu \mathrm{g} / \mathrm{mL}$ ) and $I_{\max }$ is themaximumcurrentdensity observed (in $\mathrm{mAcm}^{-2}$ ). Theapparent dissociation constant $\left(K_{\mathrm{D}}\right)$ and maximum binding capacity $\left(B_{\max }\right)$ were calculated from these data. $K_{\mathrm{D}}$ was the protein concentration required to provide half of the maximum response produced by the device.

$l_{\mathrm{S}}=\frac{l_{\max }}{1+\left(K_{\mathrm{D}} /[S]\right)}$

\subsection{Electrochemical assays}

All CV, SWV and EIS measurements were conducted in triplicate with $5.0 \mathrm{mmol} / \mathrm{L}\left[\mathrm{Fe}(\mathrm{CN})_{6}\right]^{3-}$ and $5.0 \mathrm{mmol} / \mathrm{L}\left[\mathrm{Fe}(\mathrm{CN})_{6}\right]^{4-}$, prepared
(A)

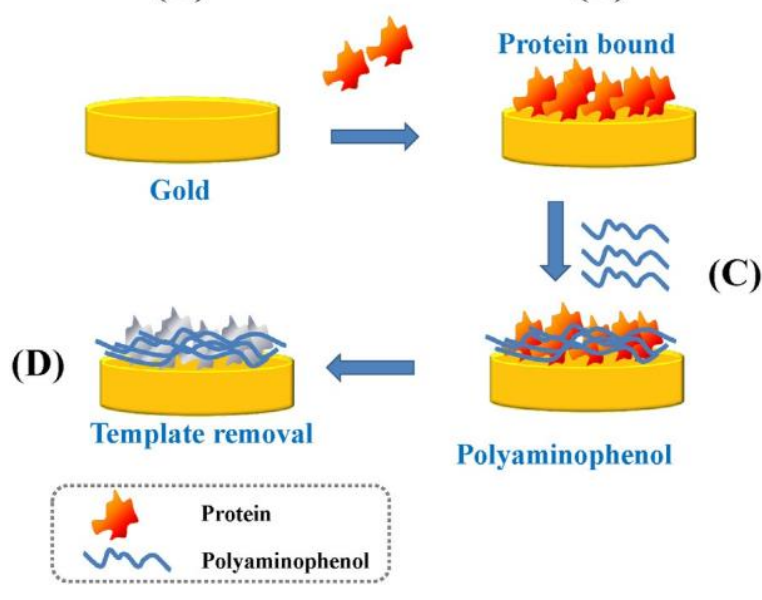

Fig. 1. Schematic representation of the synthetic process of MI. A: Au-SPE; B: Myo adsorption on Au-SPE surface; C: electropolymerization of AP; and D: binding site formation by template removal with proteinase $\mathrm{K}$.

in MES buffer of pH 5.0 used as redox probe. In CV assays the potentials were scanned from 0.2 to $+0.8 \mathrm{~V}$, at $50 \mathrm{mV} / \mathrm{s}$; in SWV potentials changed from $\_0.5$ to $+0.6 \mathrm{~V}$, at a frequency of $50 \mathrm{~Hz}$ and a step height of $150 \mathrm{mV}$; and in EIS a standard potential of $+0.12 \mathrm{~V}$ was set, using a sinusoidal potential perturbation of $0.01 \mathrm{~V}$ amplitude and 50 frequency values, logarithmically distributed over a frequency range of $0.1-100 \mathrm{kHz}$.

Calibration curves were performed by SWV and EIS measurements for Myoglobin in the range of $0.05-53.3 \mu \mathrm{g} / \mathrm{mL}$, in MES buffer $\mathrm{pH} 5$. Selectivity studies were conducted by competitive assay between Myo, with a $4.0 \mu \mathrm{g} / \mathrm{mL}$ concentration, and other interfering species. The interfering species selected for this purpose were other cardiac biomarkers that may co-exist with Myo in biological fluids: TnT $(0.22 \mu \mathrm{g} / \mathrm{mL})$ and CKMB $(0.5 \mu \mathrm{g} / \mathrm{mL})$. All these were prepared in MES buffer $\mathrm{pH}$ 5.0.

Myo determination in samples was performed by SWV measurements. Myo was prepared in synthetic serum diluted 50 times in a range between 0.053 and $53.0 \mu \mathrm{g} / \mathrm{mL}$.

\section{Results and discussion}

\subsection{Assembly of the responsive polymer}

Molecular imprinting was performed by electropolymerization of the AP monomer by CV using Myo as a templatemolecule(Fig. 2). The overall process consisted of 3 different stages: (1) Myo adsorption on the Au surface of the working electrode; (2) imprinting stage by PAP thin film formation on the Au/Myo surface; (3) and Myo removal from the PAP film by protease activity (Fig. 1). All these stages caused changes in the electron transfer properties of receptorsurface, and were thereforefollowed by EIS and CV assays.

\subsubsection{Protein adsorption}

As with any other protein, Myo binding to gold is a very complex process that may be driven by different forces between the protein and the surface, including van-der-Waals, hydrophobic and electrostatic interactions. Overall, the adsorption of Myo to the solid support is expected to involve transport from the solution to the interface, binding to the surface and subsequent relaxation via conformational adaptations [41]. Adsorption occurs due to the energetically favourable expulsion of solute from solution into the interphase between bulk solid and solution phase, along with the reduction of interfacial energetics resulting from the replacing of water molecules by adsorbed solute at the solid surface [42]. 

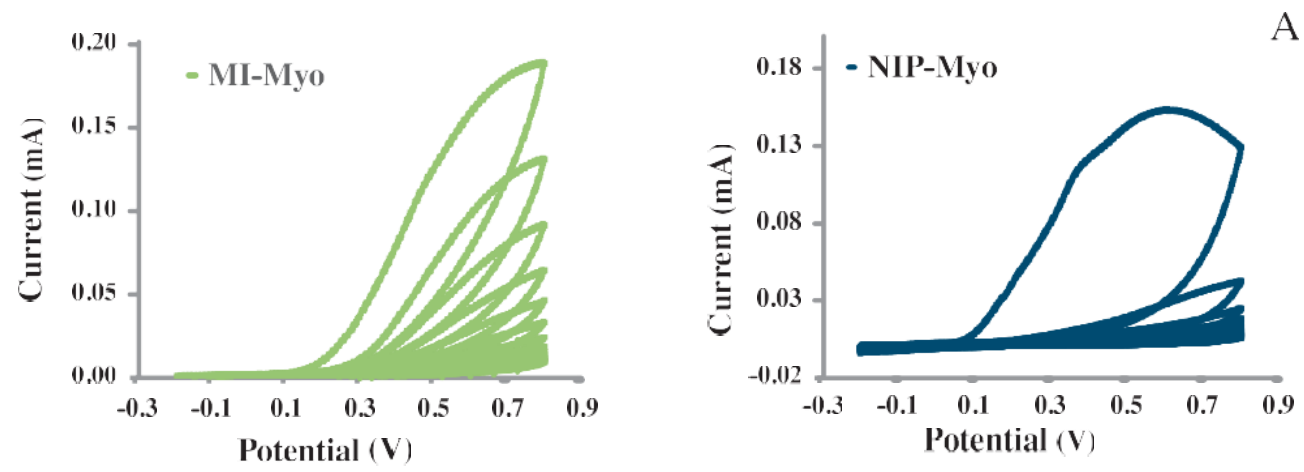

- MI/Myo

- MI/Myo Proteinase K
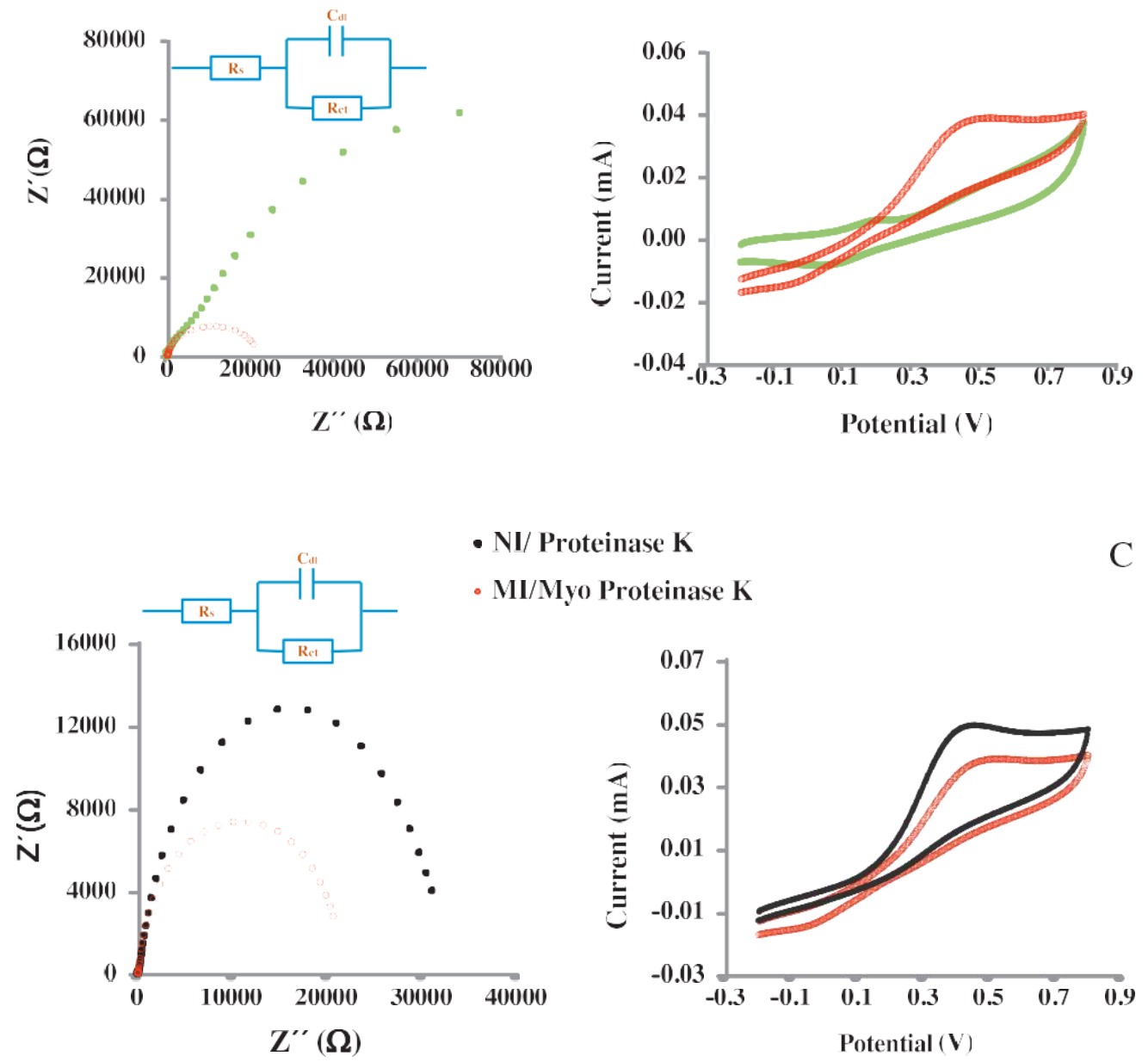

$\mathrm{C}$

MI/Myo Proteinase K

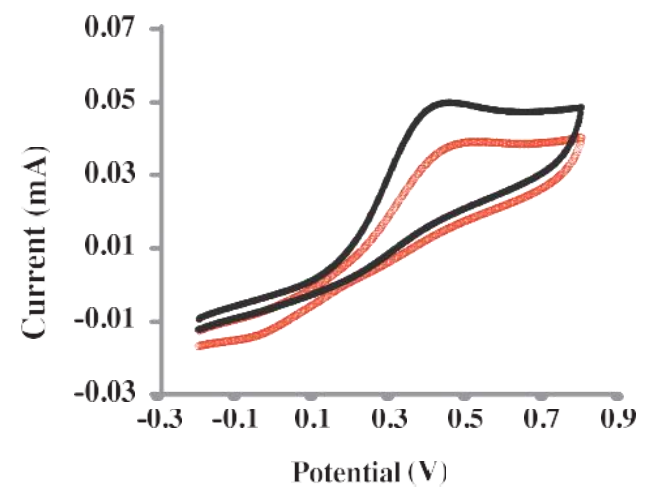

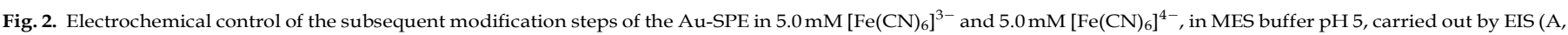
Nyquist plots) and CV (B, cyclic voltammograms) assays for MI/NI.

In addition, this interphase separating bulk solution and surface phases may range from few to $100 \mathrm{~nm}$ and proteins may apparently be adsorbed in multilayers at this interphase.

In the present study, Myo was adsorbed directly to the Au-SPE layer, just as indicated in Fig. 1A. This was done by placing a drop of Myo, prepared in acetate buffer $\mathrm{pH} 5$, in the working electrode area. The incubation period was set to $15 \mathrm{~min}$, at $4{ }^{\circ} \mathrm{C}$. The adsorption of Myo to gold increases the charge transfer resistance $\left(R_{\mathrm{ct}}\right)$ signals in the EIS spectra.

\subsubsection{Imprinting stage}

The imprinting stage was conducted by electropolymerization on the Au-SPE/Myo in an AP solution of $\mathrm{pH} 5$, by consecutive potential sweeps in CV mode and the MI device is identified as $\mathrm{Au}-\mathrm{SPE} / \mathrm{Myo} / \mathrm{PAP}$. Many electrosynthesized polymers have been produced so far in molecular imprint-based materials [43], but PAP films exhibit several advantages, including an easy control of the polymer thickness within $10-50 \mathrm{~nm}$ due to a self-limiting growth and an easy regeneration process after use [44-46]. In addition, 


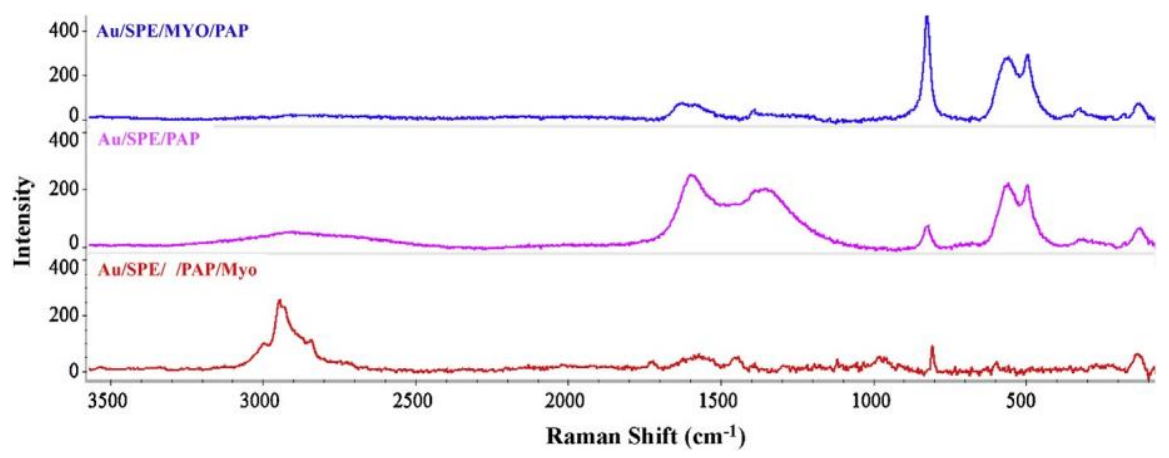

Fig. 3. RAMAN spectra for: Au-SPE/Myo/PAP; Au-SPE/Myo; Au-S PE/ - /PAP and Au-SPE.

PAP is a permselective polymer with an interfering-free effect from some electroactive species present in biological fluids, such ascorbic and uric acid [46].

Because it is fundamental to maintain the conformation of the protein template upon polymerization, imprinting was established in aqueous environment [47]. While hydrophobic interactions caused by the exclusion of water are frequently employed with success [47], the dominant forms of template-receptor complexation in aqueous protein imprinted materials involve the cooperative effect between hydrogen bond formation and hydrophobic interaction [48]. So, considering that phenoxazine elements are the main units of the MI polymeric material [49], hydrophobicinteractions are expected between the aromatic moieties of the polymer and the few hydrophobic residues that may remain on the outer surface of Myo in aqueous environment. Hydrogen bonding may also be established between some of the many polar residues remaining on the outer surface of the protein and theO/Natoms of the polymer backbone.

In the course of electropolymerization, the current decreased, and when 15 cycles were reached, the current density of the oxidation peak was much smaller (Fig. 2A, left). No reduction peak was observed during electropolymerization, which also confirmed the growth of an insulator polymer layer on the Au-SPE electrode. Overall, theseevents confirmed the formation of the PAP film above Myo, because it displaysnon-conductive proprieties [44,50,51]. The obtained film was also evident to human eye, as the gold of the SPE became dark-brown. Its thickness is expected below $50 \mathrm{~nm}$, due to the self-limiting effect, caused by thelow polymer film conductivity [50].

In general, the EIS data obtained with Au-SPE/Myo/PAP was consistent with the formation of an insulating layer. The typically low $R_{\text {ct }}$ from gold increased in an expected fashion, reaching values more than $60 \mathrm{kQ}$ (Fig. 2B, left).

The Randles equivalent circuit is normally used to explain the electrochemical proprieties of the electrode-solution interfaces with the occurrence of Faradaic current diffusion transport [52,53]. Nevertheless, Warburg'simpedance part waslacking after the PAP film formation. In this case, the equivalent circuit consists of one resistor (solution resistance $\left(R_{\mathrm{S}}\right)$ ) in series with one parallel circuit comprised of a resistor (charge transfer resistance $\left(R_{\mathrm{ct}}\right)$ ) and a capacitance due to the double layer $\left(C_{\mathrm{dl}}\right)[52,54,55]$. The Nyquist plot of a Randles cell consists of a semicircle. At high frequencies the impedance of $C_{\mathrm{dl}}$ is very low, and very low frequencies the impedance of $C_{\mathrm{dl}}$ becomes high, and thus, the measured impedance tends to $\left(R_{\mathrm{ct}}+R_{\mathrm{s}}\right)$. The diameter of the semicircle is identical to the charge-transfer resistance [56].

In parallel, a negative control was also employed to create a NI film (Au-SPE/PAP). This was done by carrying out the electropolymerization stage over a clean Au-SPE support that did not contact Myo (Fig. 2A, right). The CV of such electropolymerization was quite similar to that observed in the production of the Au-SPE/Myo/PAP film, producing a continuouscurrent decreasein subsequentcycles. Compared to the MI film, an additional oxidative peak was evident at about $0.5 \mathrm{~V}$. This was probably a result of the absence of the Myo layer that acted as a barrier to electrical transfer in the MI film.

\subsubsection{Protein removal}

Many strategies for removing protein form imprinted polymers have been described to date. These include mostly chemical treatments that look for protein denaturation and amide bond cleavage [57-61]. Most recently, we have proposed the use of enzymes displaying proteolytic activity capable of cleaving peptide bonds [28]. Enzymes are effective and act under mild conditions, thus preventing significant alterations at the polymeric network.

The Au-SPE/Myo/PAP film with Myo was therefore incubated overnight with Proteinase K $500 \mu \mathrm{g} / \mathrm{mL}$. Proteinase $\mathrm{K}$ is a highly active and stable protease with low specificity regarding the peptide bond environment and high efficiency in cleaving the amide bond. The resulting peptide fragments from Myo, along with the free enzyme, were after removed by washing thoroughly the surface. This meant to ensure that the imprinted sites were free for Myo rebinding.

In general, part of the electron transfer ability of the MI film was recovered by protein removal (Au-SPE/-/PAP) (Fig. 2B), thus indicating that Myo was successfully extracted from the PAP layer. This was also confirmed by a similar EIS behaviour between AuSPE/-/PAP and Au-SPE/PAP film after protease action (Fig. 2C, left). Their little difference in Rct is probably confirming the presence of the binding sites that facilitated the electron transfer due to their smaller distance to the $\mathrm{Au}$ layer. $\mathrm{CV}$ data also confirmed a close behaviour between Au-SPE/PAP and Au-SPE/-/PAP films after protease activity (Fig. $2 \mathrm{C}$, right). The oxidation peak observed at $0.5 \mathrm{~V}$ after protein removal is possibly accounted for by the absence of the protein and hence increased film porosity.

\subsection{Qualitative analysis}

The chemical profile of the Au-SPE/PAP, Au-SPE/Myo/PAP and Au-SPE/-/PAP films was assessed by RAMAN analysis with Confocal microscopy (Fig. 3), FTIR (Fig. 4).

\subsubsection{Raman spectrometry}

Raman spectra were recorded for Au/SPE/PAP and $\mathrm{Au} / \mathrm{SPE} / \mathrm{Myo} / \mathrm{PAP}$ surfaces, acting as imprinted and non-imprinted surfaces. The typical images obtained are presented in Fig. 3.

Regarding PAP films, the evidence of peaks at about 1400 and $1600 \mathrm{~cm}^{-1}$ Raman shift were assigned to quinoid groups of 3 -aminophenoxazone (APZ) and to the aromatic ring/- $-\mathrm{N}-$ in quinonimine units, respectively [62-64], from the PAP films. The PAP electropolymerization is expected toyield two main products: 


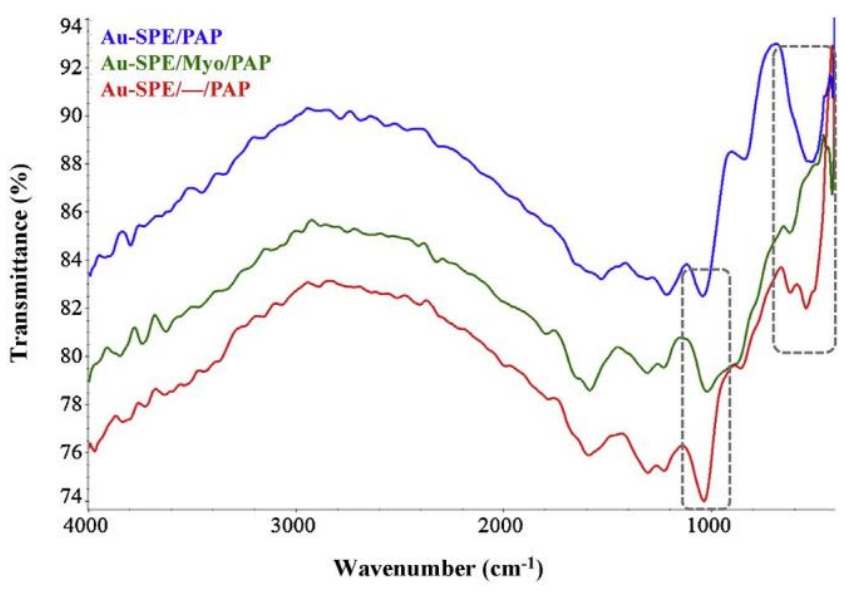

Fig. 4. FTIR spectra for: Au-SPE/ - /PAP; Au-SPE/Myo/PAP and Au-SPE/PAP.

APZ and 2,2-dihydroxyazobenzene (DHAB). APZ is cyclic dimer, by the simultaneous $\mathrm{N}-\mathrm{C}$ and $\mathrm{O}-\mathrm{C}$ coupling of $\mathrm{AP}$ monomer units, obtained especially under acidic $\mathrm{pH}$ conditions. APZ can be oxidized further at the electrode forming the ladder structured polymer [62]. DHAB is formed mostly in neutral and basic solutions.

Spectra of PAP films produced over an SPE that had adsorbed Myo showed a significant reduction of the Raman shift at about 1400 and $1600 \mathrm{~cm}^{-1}$. Possibly this decrease could be linked to the presence of Myo on the surface, acting as a barrier to polymer growth and reticulation.

The protein rebinding to the imprinted film was also confirmed by Raman spectroscopy. The spectra obtained, Au/SPE/PAP/Myo, showed a large band at $3000 \mathrm{~cm}^{-1}$, assuming that the plane $\mathrm{z}$ used for recording the spectra was above the PAP film. These Raman shifts corresponded to the $\mathrm{C}-\mathrm{H}$ stretching region $\left(2800-3100 \mathrm{~cm}^{-1}\right)$ of various amino acids in proteins $[65,66]$. Overall, the band near $2940 \mathrm{~cm}^{-1}$ was attributed to aromatic and aliphatic amino acids and as well to many other amino acids; a band near $3065 \mathrm{~cm}^{-1}$ appears was correlated to aromatic residues; while bands near 2880 and $2900 \mathrm{~cm}^{-1}$ corresponded primarily to aliphatic amino acids [66].

\subsubsection{Fourier transformed infrared spectrometry}

As in Raman assays, the FTIR analysis was conducted directly over the SPEs. When this analysis was conducted with an attenuated total reflectance (ATR) accessory, the transmittance data was always accounted as major signal the background Au layer at the working electrode. So, a Specular Apertured Grazing Angle (SAGA) accessory was employed as it enabled the optical beam to be focused tangentially on the electrode, thus allowing identification of small changes taking place at the outer surface of this active layer. The major drawback of such an approach was the decrease in the signal intensity, but this was compensated by an increased number of readings.

The FTIR data obtained with Au-SPE/PAP, Au-SPE/Myo/PAP, and Au-SPE/ - / PAP electrodes are shown in Fig. 4. The common peaks at $\sim 1600 \mathrm{~cm}^{-1}$ wavenumber were assigned to the carbonyl group and/or to the characteristic $-\mathrm{C} \bigoplus$ stretching in $3 \mathrm{APZ}$, resulting from the PAP film. The common peaks located at $850 \mathrm{~cm}^{-1}$ were assigned to $-\mathrm{C}-\mathrm{H}$ bending vibration of aromatic ortho-substituted aromatic rings, also resulting from PAP. The absence of hydroxyl group absorption at $3500 \mathrm{~cm}^{-1}$ could be attributed to a low proportion of a linear chain polymer structure.

Overall, the differences within the three spectra are confined to two regions that seem to account the presence or removal of Myo (Fig. 4). Comparing Au-SPE/PAP with Au-SPE/Myo/PAP, the presence of Myo in the later leads to an increased absorption at the
$1020 \mathrm{~cm}^{-1}$ and to a decreased absorption at $520 \mathrm{~cm}^{-1}$. The removal of Myofrom thefilm Au-SPE/Myo/PAPis detected by the recovery of the peak at $520 \mathrm{~cm}^{-1}$ in the FTIR spectra of Au-SPE/ - /PAP. The presence of some Myo inside the polymer was also evidenced by the presence of a small peak at $600 \mathrm{~cm}^{-1}$, which was also present in Au-SPE/Myo/PAP film.

Overall, the combined information of the FTIR spectra confirm the presence of the PAP film over the Au-SPE, the presence of Myo at the MI film and its partial removal after protease action.

\subsection{Analytical performance of the sensor}

SWVandEIScalibrationcurveswererecorded for Au-SPE/ - /PAP and Au-SPE/PAP electrodes. The calibrations plotted current intensity $\left(I\right.$, in SWV) or $R_{\mathrm{ct}}$ (in EIS) against logarithm Myo concentration, ranging from 0.05 to $53.3 \mu \mathrm{g} / \mathrm{mL}$ at $\mathrm{pH} 5$ (Fig. $5 \mathrm{~A}$ and B). In general, the presence of Myo in the redox probe concomitantly decreased the current of the typical anodic peak at $0.4 \mathrm{~V}$, while increasing the resistance on Au-SPE surface.

Regarding EIS data, the $R_{\mathrm{ct}}$ values in the Nyquist plots, increased linearly with the increasing of the logarithm of Myo concentration after $4.0 \mu \mathrm{g} / \mathrm{mL}$ (Fig. 5B). The slope average was $11.0 \mathrm{kQ} /$ decade $l o g$ [Myo, $\mu \mathrm{g} / \mathrm{mL}$ ] and the squared correlation coefficients $>0.988$. The detection limit was $3.53 \mu \mathrm{g} / \mathrm{mL}$, corresponding to the concentration of the cross-section of the two linear parts of the response. In the NI sensor, $R_{\mathrm{ct}}$ increase with the increasing of the logarithm of Myo concentration after $16.0 \mu \mathrm{g} / \mathrm{mL}$, but with squared correlation coefficients $>0.895$. These results showed a random behavior, showing that the imprinting recognition of Myo was governing the electrical response of the MI electrode.

In SWV assays, the Au-SPE/ - /PAP sensor showed linear behaviour down to $2.22 \mu \mathrm{g} / \mathrm{mL}$, with a slope $0.0247\left({ }_{ \pm} 0.003\right)$ $\mu \mathrm{A} /$ decade $\log$ [Myo, $\mu \mathrm{g} / \mathrm{mL}$ ] and squared correlation coefficients $>0.999$. The LOD was equal to $0.827 \mu \mathrm{g} / \mathrm{mL}$.

The NI sensor, Au-SPE/PAP, displayed linear behavior after $16 \mu \mathrm{g} / \mathrm{mL}$, with the slope $0.0142 \mu \mathrm{A} /$ decade $\log$ [Myo, $\mu \mathrm{g} / \mathrm{mL}$ ] and squared correlation coefficients $>0.995$. The repeatability of the response was good, with standard deviations below than $5 \%$.

Overall,SWV showed quicker, moresensitiveand moreselective responses to Myo, when compared to EIS assays. So, this electrochemical approach was selected for further studies.

\subsection{Binding isotherm}

MI creates binding cavities that are expected to be complementary to the shape and functionality of the protein. The rebinding properties of the MI film after and before electrochemical cleaning with PBS were evaluated by the binding equilibrium experiments. NI films were also included in this study for comparison purposes.

The Langmuir isotherm model was used to fit the experimental data and the results are shown in Fig. 6. The dissociation constant $\left(K_{\mathrm{D}}\right)$ indicates the necessary Myo concentration to reach one half of the maximal velocity for the reaction. This constant is thus a combination of the amount of Myo bound to the film and its affinity. A low $K_{\mathrm{D}}$ indicates a large binding affinity, as the reaction will approach the maximum velocity $\left(V_{\text {máx }}\right)$ more rapidly, while a high $K_{\mathrm{d}}$ indicates that the sensor does not bind as efficiently to Myo, and the maximum binding capacity $\left(B_{\max }\right)$ will only be reached if the Myo concentration is high enough to saturate the binding sites in the film.

In general, MI showed better features in terms $B_{\max }$ and $K_{\mathrm{D}}$ comparing with NI film. But, the most important information regards the need of electrochemical cleaning after protease activity to ensure the good affinity of Myo to the Au-SPE/ - / PAP film. This stage is required to ensure complete removal of unreacted organic 

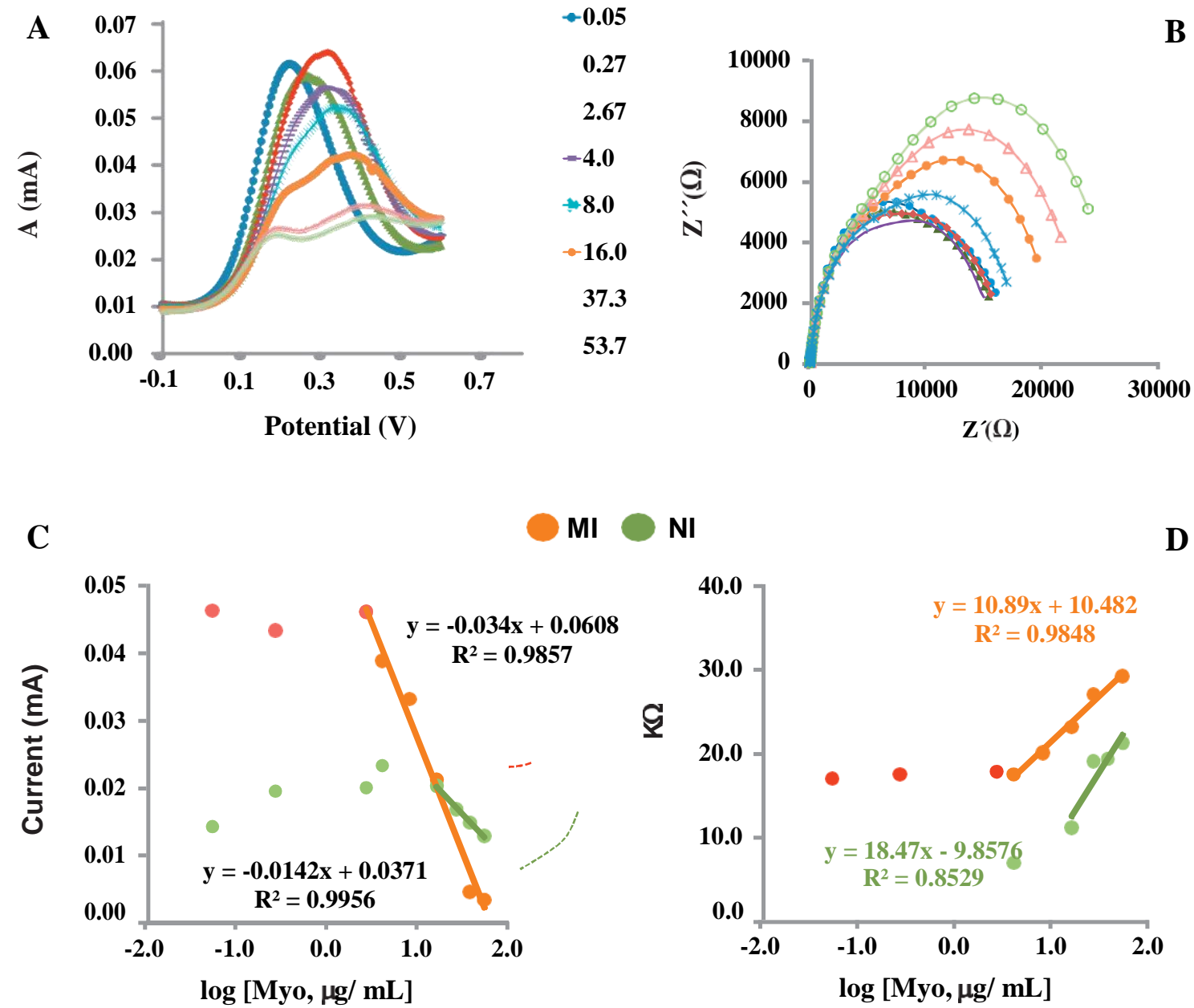

NI

D

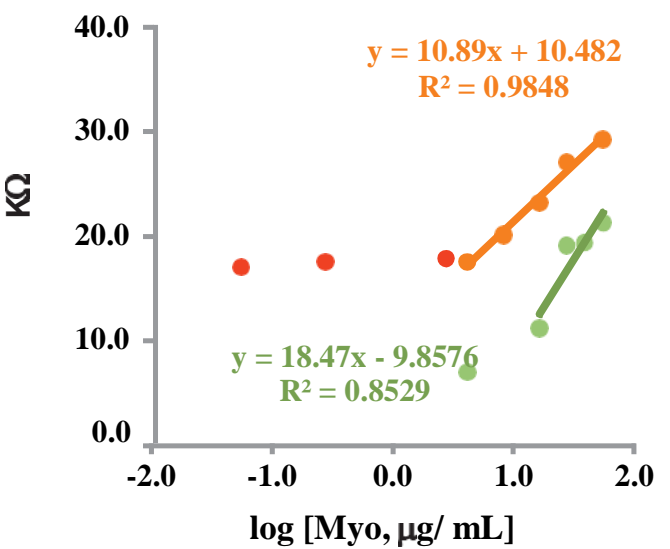

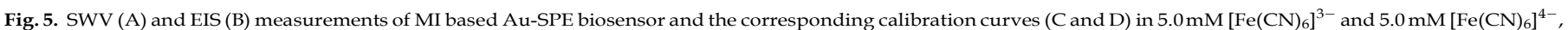
in MES buffer pH 5, with different concentrations of Myo. Calibration curves of NI based Au-SPE are also included de B and D.

compounds such as traces of monomers on its surface. These compounds shall promote a barrier, hindering the protein to reach its binding sites. The $B_{\text {máx }}$ and $K_{\mathrm{D}}$ values for this were $0.042 \mathrm{~mA}$ and $10 \mu \mathrm{g} / \mathrm{mL}$, respectively.

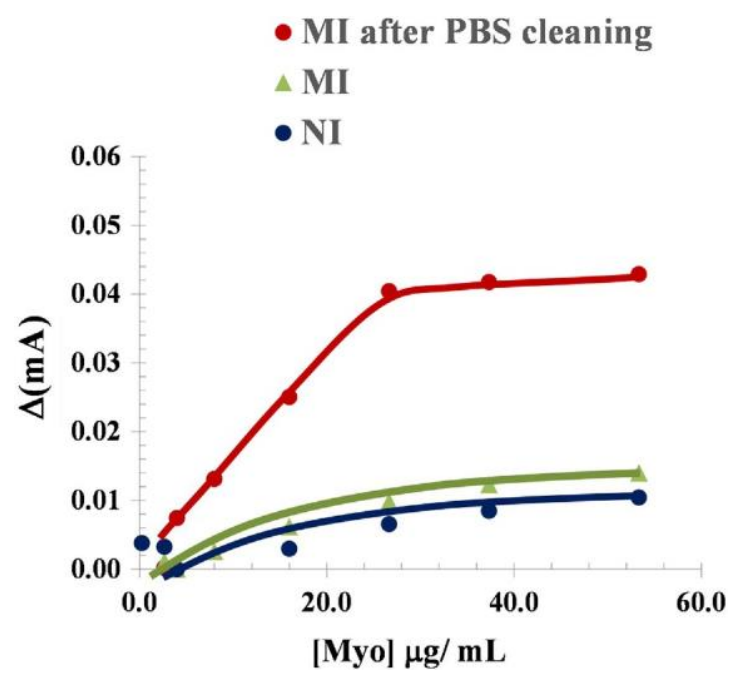

Fig. 6. Graphical representation of the Langmuir isotherm plot, $I_{\max }$ and $K_{\mathrm{D}}$ values, for MI (before and after electrochemical surface cleaning) and NI materials.

\subsection{Selectivity study}

Selectivity study used SWV measurements of the Au-SPE/ - /PAP electrodes for solutions of only Myo or Myo + interfering species. The incubation period of the sensor with these solutions was set to 10 minutes, to ensure that equilibrium as always reached, even when interfering species were present. The interfering species tested were TnT and CKMB, other cardiac biomarkers presents in serum. Their concentrations were set to their typical values in this biological fluid. The \% deviation produced by each interfering species in pure Myo solutions were $12 \%$ for TnT and $8 \%$ for CKMB respectively. The repeatability of the results accounted standard deviations below $5 \%$.

Overall, the interference from the above proteins was considered negligible, meaning that the MI electrodes, Au-SPE/ - / PAP, may provide accurate data under the analysis of real samples.

\subsection{Sample analysis}

Because no access to real samples was possible, synthetic serum samples were used to assess the possible application of the device. For this purpose, instead of a normal sample application, the calibration was made in a background of synthetic serum and compared to that made previously in buffer. The results obtained are presented in Fig. 7.

In general, spiked serum samples showed good features in terms of lower concentration of the linear concentration range, LOD 

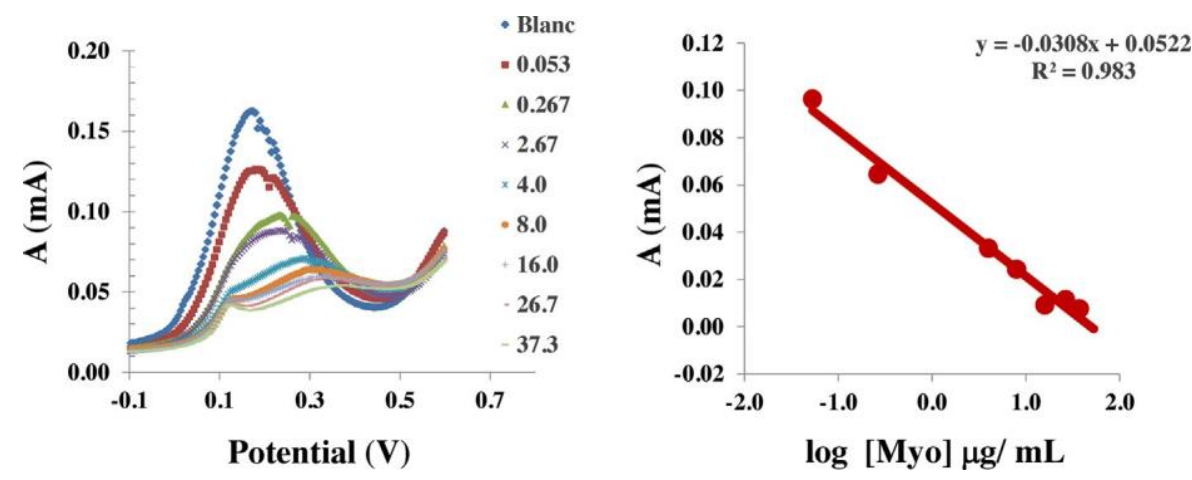

Fig. 7. SWV measurements of MI based Au-SPE biosensor and the corresponding spiked serum samples with different concentrations of Myo.

and slope $\left(0.05 \mu \mathrm{g} / \mathrm{mL}, 0.01 \mu \mathrm{g} / \mathrm{mL}\right.$ and $\_0.0308 \mu \mathrm{A} /$ decade[Myo, $\mu \mathrm{g} / \mathrm{mL}]$ ) respectively. Comparing with the Myo calibration curve in MES buffer $\mathrm{pH}$ 5, the LOD is lower accounting a negligible interference of the serum matrix. All assays were performed 3 repeated measurements.

\section{Conclusions}

The effective combination of electrochemistry and MI technology in an analytical device provides a promising tool for direct electrical detection of proteins. The adsorption of protein over the conductive layer promoting the electrosynthesis of the polymeric film seemed to be a successful imprinting approach. This new approach may lead to further improvements within the electropolymerization imprinted materials, by contributing with a new way of forming the imprinted film.

The present biosensor does not have a better analytical performance than most of the previous devices employing molecular imprinting procedures $[67,68,28,25]$. However, its response is among the range of concentration of clinical significance and the device set-up is by far the quicker, the simplest and the cheaper process presented so far. Compared to previous immunosensors $[69,70]$ it also offers reusability, which is a very useful feature in routine applications.

In general, the biosensor presented here demonstrates simplicity in designing, short measuring time, reusability, high accuracy, low limit of detection and good selectivity. This approach seems a successful tool for screening cardiac biomarkers in point of care.

\section{Acknowledgements}

One of the authors (FTCM) gratefully acknowledges Fundação para a Ciência e Tecnologia for the financial support (PhD grant reference SFRH/BD/66735/2009 | intituled “Fast screening for early diagnostic of heart ischemic episodes").

\section{References}

[1] EuroStat, http://ec.europa.eu/health/major_chronic_diseases/indicators/ index_en.htm, volume 2010, assessed in the 10th August 2013.

[2] A. Qureshi, Y. Gurbuz, J.H. Niazi, Biosensors for cardiac biomarkers detection: a review, Sensors and Actuators B-Chemical 171 (2012) 62-76.

[3] K. Lewandrowski, A. Chen, J. Januzzi, Cardiac markers for myocardial infarction. A brief review, American Journal of Clinical Pathology 118 (Suppl.) (2002).

[4] B. McDonnell, S. Hearty, P. Leonard, R. O'Kennedy, Cardiac biomarkers and the case for point-of-care testing, Clinical Biochemistry 42 (7-8) (2009) 549-561.

[5] U. Friess, M. Stark, Cardiac markers: a clear cause for point-of-care testing, Analytical and Bioanalytical Chemistry 393 (5) (2009) 1453-1462.

[6] G. de Couto, M. Ouzounian, P.P. Liu, Early detection of myocardial dysfunction and heart failure, Nature Reviews Cardiology 7 (6) (2010) 334-344.

[7] F.S. Apple, A. Falahati, P.R. Paulsen, E.A. Miller, S.W. Sharkey, Improved detection of minor ischemic myocardial injury with measurement of serum cardiac troponin I, Clinical Chemistry 43 (11.) (1997).
F. Crivellente, M. Tontodonati, N. Fasdelli, A. Casartelli, R. Dorigatti, I. Faustinelli, P. Cristofori, NT-proBNP as a biomarker for the assessment of a potential cardiovascular drug-induced liability in beagle dogs, Cell Biology and Toxicology 27 (6.) (2011).

[9] Chronolab, http://www.chronolab.com/point-of-care/index.php?option = com_content\&view $=$ article\&id $=343 \&$ Itemid $=55$, The Clinical Chemistry Point of Care, volume assessed in the 13th August 2013, 2013.

[10] http://www.alere.com/EN US/products/alere-triage-cardiac-panel-poc-test/ index.html, assessed 29th August 2012.

[11] S. Ray, P.J. Reddy, S. Choudhary, D. Raghu, S. Srivastava, Emerging nanoproteomics approaches for disease biomarker detection: a current perspective, Journal of Proteomics 74 (12) (2011) 2660-2681.

[12] P. Li, G.D.Y. Deng, D. Punyapitak, D. Li, Y. Cao, Free Radical Biology and Medicine 65 (2013) 224-231.

[13] L. Denoroy, L. Zimmer, B. Renaud, S. Parrot, Ultra high performance liquid chromatography as a tool for the discovery and the analysis of biomarkers of diseases: a review, Journal of Chromatography B - Analytical Technologies in the Biomedical and Life Sciences 927 (2013) 37-53.

[14] C. Gouvea, Biosensors for health applications, in: Biosensors for Health, Environment and Biosecurity, InTech, 2011.

[15] A. May, T.J. Wang, Biomarkers for cardiovascular disease: challenges and future directions, Trends in Molecular Medicine 14 (6.) (2008).

[16] R. Simon, M.E. Collins, D.A. Spivak, Shape selectivity versus functional group pre-organization in molecularly imprinted polymers, Analytica Chimica Acta 591 (1) (2007) 7-16.

[17] X. Luo, J.J. Davis, Electrical biosensors and the label free detection of protein disease biomarkers (2013)

[18] A. Bossi, F. Bonini, A.P.F. Turner, S.A. Piletsky, Molecularly imprinted polymers for the recognition of proteins: the state of the art, Biosensors \& Bioelectronics 22 (6) (2007) 1131-1137.

[19] R. Schirhagl, U. Latif, D. Podlipna, H. Blumenstock, F.L. Dickert, Natural and biomimetic materials for the detection of insulin, Analytical Chemistry 84 (9) (2012) 3908-3913.

[20] D. Kriz, O. Ramstrom, K. Mosbach, Molecular imprinting - new possibilities for sensor technology, Analytical Chemistry 69 (11) (1997) A345-A349.

[21] L. Ye, K. Mosbach, Molecularly imprinted microspheres as antibody binding mimics, Reactive \& Functional Polymers 48 (1-3) (2001) 149-157.

[22] A. Rachkov, N. Minoura, Towards molecularly imprinted polymers selective to peptides and proteins. The epitope approach, Biochimica Et Biophysica Acta-Protein Structure and Molecular Enzymology 1544 (1-2) (2001) $255-266$.

[23] M.J. Whitcombe, I. Chianella, L. Larcombe, S.A. Piletsky, J. Noble, R. Porter, A. Horgan, The rational development of molecularly imprinted polymer-based sensors for protein detection, Chemical Society Reviews 40 (3) (2011).

[24] Y. Wang, Y. Zhou, J. Sokolov, B. Rigas, K. Levon, M. Rafailovich, A potentiometric protein sensor built with surface molecular imprinting method, Biosensors \& Bioelectronics 24 (1) (2008) 162-166.

[25] F.T.C. Moreira, R.A.F. Dutra, J.P.C. Noronha, M.G.F. Sales, Myoglobin-biomimetic electroactive materials made by surface molecular imprinting on silica beads and their use as ionophores in polymeric membranes for potentiometric transduction, Biosensors \& Bioelectronics 26 (12) (2011) 4760-4766.

[26] A.V. Linares, A. Falcimaigne-Cordin, L.A. Gheber, K. Haupt, Patterning nanostructured, synthetic, polymeric receptors by simultaneous projection photolithography, nanomolding, and molecular imprinting, Small 7 (16) (2011) 2318-2325.

[27] F.T.C. Moreira, R.A.F. Dutra, J.P.C. Noronha, A.L. Cunha, M.G.F. Sales, Artificial antibodies for troponin $\mathrm{T}$ by its imprinting on the surface of multiwalled carbon nanotubes: its use as sensory surfaces, Biosensors \& Bioelectronics 28 (1) (2011) 243-250.

[28] F.T.C. Moreira, S. Sharma, R.A.F. Dutra, J.P.C. Noronha, A.E.G. Cass, M.G.F. Sales, Smart plastic antibody material (SPAM) tailored on disposable screen printed electrodes for protein recognition: application to myoglobin detection, Biosensors \& Bioelectronics 45 (2013) 237-244.

[29] B. Osman, U.L. Beșirli, N.A. Denizli, Microcontact imprinted surface plasmon resonance sensor for myoglobin detection, Materials Science \& Engineering C, Materials for Biological Applications 33 (7) (2013) 3609-3614. 
[30] N. Karimian, V.M. Zavar, M.H. Chamsaz, M. Turner, A.P.A. Tiwari, An ultrasensitive molecularly-imprinted human cardiac troponin sensor, Biosensors and Bioelectronics 50C (2013) 492-498.

[31] T. Panasyuk, V.C. Dall'Orto, G. Marrazza, A. El'skaya, S. Piletsky, I. Rezzano, M Mascini, Molecular imprinted polymers prepared by electropolymerization of Ni-(Protoporphyrin IX), Analytical Letters 31 (11) (1998) 1809-1824.

[32] D. Cai, L. Ren, H. Zhao, C. Xu, L. Zhang, Y. Yu, H. Wang, Y. Lan, M.F. Roberts, J.H. Chuang, et al., A molecular-imprint nanosensor for ultrasensitive detection of proteins, Nature Nanotechnology 5 (8) (2010) 597-601.

[33] U.Lange, N.V.Roznyatouskaya, V.M.Mirsky, Conducting polymers inchemical sensors and arrays, Analytica Chimica Acta 614 (1) (2008) 1-26.

[34] C. Malitesta,I.Losito, P.G.Zambonin, Molecularly imprinted electrosynthesized polymers: new materials for biomimetic sensors, Analytical Chemistry 71 (7) (1999) 1366-1370.

[35] A.M. Castaldo, P. Ercolini, F. Forino, A. Basevi, L. Vrenna, P. Castaldo, V.D. Ambrosio, A. Castaldo, Plasma myoglobin in the early diagnosis of acute myocardial-infarction, European Journal of Clinical Chemistry and Clinical Biochemistry 32 (5) (1994) 349-353.

[36] E.M. Balk, J.P.A. Ioannidis, D. Salem, P.W. Chew, J. Lau, Accuracy of biomarkers to diagnose acute cardiac ischemia in the emergency department: a metaanalysis, Annals of Emergency Medicine 37 (5) (2001) 478-494.

[37] H. Dyan, Cardiac markers for acute myocardial infarction: when should we test? Canadian Medical Association Journal 163 (9) (2000).

[38] H.S. Lee, S.J. Cross, P. Garthwaite, A. Dickie, I. Ross, S. Walton, K. Jennings, Comparison of the value of novel rapid measurement of myoglobin, creatine-kinase, and creatine kinase- $\mathrm{mb}$ with the electrocardiogram for the diagnosis of acute myocardial-infarction, British Heart Journal 71 (4) (1994) 311-315.

[39] A. Grand, T. Laperche, J. Fruchaud, Y. Fournis, J. Benessiano, E. Sauser, Value of early serum myoglobin assay for the diagnosis of acute myocardial-infarction, Archives Des Maladies Du Coeur Et Des Vaisseaux 87 (6) (1994) 729-735.

[40] M. Zayats, M. Kanwar, M. Ostermeier, P.C. Searson, Molecular imprinting of maltose binding protein: tuning protein recognition at the molecular level, Macromolecules 44 (10) (2011) 3966-3972.

[41] J. Voros, The density and refractive index of adsorbing protein layers, Biophysical Journal 87 (1) (2004) 553-561.

[42] E.A. Vogler, Structure and reactivity of water at biomaterial surfaces, Advances in Colloid and Interface Science 74 (1998) 69-117.

[43] C. Alexander, H.S. Andersson, L.I. Andersson, R.J. Ansell, N. Kirsch, I.A. Nicholls, J. O'Mahony, M.J. Whitcombe, Molecular imprinting science and technology: a survey of the literature for the years up to and including 2003, Journal of Molecular Recognition 19 (2) (2006) 106-180.

[44] S.M.Sayyah,M.M.El-Rabiey,S.S.AbdEl-Rehim, R.E. Azooz, Electropolymerization kinetics of o-aminophenol and characterization of the obtained polymer films, Journal of Applied Polymer Science 99 (6) (2006) 3093-3109.

[45] R. Tucceri, A review about the charge conduction process at poly(oaminophenol) film electrodes, The Open Physical Chemistry Journal 4 (2010) 62-77.

[46] R. Tucceri, A.P.A. Scian, Electrosynthesis and spectroscopic characterization of poly(o-aminophenol) film electrodes, ISRN Polymer Science 2012 (2012) 26pages.

[47] N.W. Turner, C.W. Jeans, K.R. Brain, C.J. Allender, V. Hlady, D.W. Britt, From 3D to 2D: a review of the molecular imprinting of proteins, Biotechnological Progresses 22 (6) (2006) 1474-1489.

[48] D.S. Janiak, P. Kofinas, Molecular imprinting of peptides and proteins in aqueous media, Analytical Bioanalytical Chemistry 389 (2007) 399-404

[49] H.J. Salavagione, J. Arias, P. Garcés, E. Morallón, C. Barbero, J.L. Vázquez, Spectroelectrochemical study of the oxidation of aminophenols on platinum electrode in acid medium, Journal of Electroanalytical Chemistry 565 (2) (2004) 375-383.

[50] O. Levin, V. Kondratieva, V. Malev, Charge transfer processes at poly-ophenylenediamine and poly-o-aminophenol films, Electrochimica Acta 50 (78) (2005) 1573-1585.

[51] M.G. Mahjani, A. Ehsani, M. Jafarian, Electrochemical study on the semiconductor properties and fractal dimension of poly ortho aminophenol modified graphite electrode in contact with different aqueous electrolytes, Synthetic Metals 160 (11-12) (2010) 1252-1258.

[52] J.S. Daniels, N. Pourmand, Label-free impedance biosensors: opportunities and challenges, Electroanalysis 19 (12) (2007) 1239-1257.

[53] I.I. Suni, Impedance methods for electrochemical sensors using nanomaterials, Trac-Trends in Analytical Chemistry 27 (7) (2008) 604-611.

[54] S.J.Ding, B.W. Chang, C.C.Wu,M.F.Lai,H.C.Chang,Impedancespectralstudies of self-assembly of alkanethiols with different chain lengths using different immobilization strategies on Au electrodes, Analytica Chimica Acta 554 (1-2) (2005) 43-51.

[55] S.J. Ding, B.W. Chang, C.C. Wu, M.F. Lai, H.C. Chang, Electrochemical evaluation of avidin-biotin interaction on self-assembled gold electrodes, Electrochimica Acta 50 (18) (2005) 3660-3666.

[56] C.S. Xiao-Zi Yuan, Haijiang Wang, Jiujun Zhang, Electrochemical Impedance Spectroscopy in PEM Fuel Cells. Fundamentals and Applications, SpringerVerlag, London, 2010, pp.420p.

[57] H-Y. Lin, J. Rick, T-C. Chou, Optimizing the formulation of a myoglobin molecularly imprinted thin-film polymer-formed using a micro-contact imprinting method, Biosensors \& Bioelectronics 22 (12) (2007) 3293-3301.

[58] A. Bossi, S.A. Piletsky, E.V.Piletska, P.G. Righetti, A.P.F. Turner, Surface-grafted molecularly imprinted polymers for protein recognition, Analytical Chemistry 73 (21) (2001) 5281-5286.
F. Bonini, S. Piletsky, A.P.F. Turner, A.Speghini, A. Bossi, Surfaceimprinted beads for the recognition of human serum albumin, Biosensors \& Bioelectronics 22 (9-10) (2007) 2322-2328.

[60] Y. Li, H.H. Yang, Q.H. You, Z.X. Zhuang, X.R. Wang, Protein recognition via surface molecularly imprinted polymer nanowires, Analytical Chemistry 78 (1) (2006) 317-320.

[61] N.W.Turner, C.W. Jeans, K.R. Brain, C.J. Allender, V.Hlady, D.W. Britt, From 3D to $2 \mathrm{D}$ : a review of the molecular imprinting of proteins, Biotechnology Progress 22 (6) (2006)

[62] B. Palys, M. Marzec, J. Rogalski, Poly-o-aminophenol as a laccase mediator and influence of the enzyme on the polymer electrodeposition, Bioelectrochemistry 80 (1) (2010) 43-48.

[63] A-u-H.A. Shah, R. Holze, Poly(o-aminophenol) with two redox processes: a spectroelectrochemical study, Journal of Electroanalytical Chemistry 597 (2) (2006) 95-102

[64] J. Li, J. Zhao, X. Wei, A sensitive and selective sensor for dopamine determination based on a molecularly imprinted electropolymer of o-aminophenol, Sensors and Actuators B-Chemical 140 (2) (2009) 663-669.

[65] G.J. Thomas, Raman spectroscopy of protein and nucleic acid assemblies, Annual Review of Biophysics and Biomolecular Structure 28 (1999) 1-27.

[66] N.K. Howell, G. Arteaga, S. Nakai, E.C.Y. Li-Chan, Raman spectral analysis in the $\mathrm{C}-\mathrm{H}$ stretching region of proteins and amino acids for investigation of hydrophobic interactions, Journal of Agricultural and Food Chemistry 47 (3) (1999) 924-933.

[67] F.T.C. Moreira, R.A.F. Dutra, J.P.C. Noronha, M.G.F. Sales, Electrochemical biosensor based on biomimetic material for myoglobin detection, Electrochimica Acta 107 (2013) 481-487.

[68] F.T.C. Moreira, R.A.F. Dutra, J.P.C. Noronha, J.C.S. Fernandes, M.G.F. Sales, Novel biosensing device for point-of-care applications with plastic antibodies grown on Au-screen printed electrodes, Sensors and Actuators B-Chemical 182 (2013) 733-740.

[69] L. Tang, K.A. Kang, Preliminary study of fiber optic multi-cardiac-marker biosensing system for rapid coronary heart disease diagnosis and prognosis. Oxygen transport to tissue XYVII, Advances in Experimental Medicine and Biology 578 (2006) 101-106.

[70] E.V.Suprun, A.L. Shilovskaya, A.V. Lisitsa, T.V. Bulko, V.V.Shumyantseva, A.I. Archakov, Electrochemical immunosensor based on metal nanoparticles for cardiac myoglobin detection in human blood plasma, Electroanalysis 23 (5) (2011) 1051-1057. 
